\title{
BENEFÍCIOS DA IMPLANTAÇÃO E CERTIFICAÇÃO DE SISTEMAS DE GESTÃO DA QUALIDADE EM EMPRESAS CONSTRUTORAS
}

\section{BENEFITS OF THE IMPLEMENTATION AND CERTIFICATION OF QUALITY MANAGEMENT SYSTEMS IN CONSTRUCTION COMPANIES}

\author{
Marcelo D. Depexe ${ }^{1}$; Edson P. Paladini ${ }^{2}$ \\ ${ }^{1}$ Universidade Federal de Santa Catarina - UFSC - Florianópolis - Brasil marcelodepexe@yahoo.com.br \\ ${ }^{2}$ Universidade Federal de Santa Catarina - UFSC - Florianópolis - Brasil paladini@deps.ufsc.br
}

\begin{abstract}
Resumo
Nos últimos anos, muitas empresas construtoras têm buscado a certificação de seus sistemas de gestão da qualidade, principalmente na ISO 9001 e PBQP-H. Diversos autores relatam o processo de implantação e certificação de sistemas de gestão da qualidade, mas geralmente abordam o processo de implementação e expectativas futuras. O presente trabalho tem o objetivo de identificar a percepção das empresas em relação aos benefícios obtidos pela implantação e certificação de sistemas de gestão da qualidade. Foi realizada uma pesquisa junto a 14 empresas construtoras na cidade de Florianópolis. Esta pesquisa é conduzida sob a forma de uma entrevista estruturada, baseada em um questionário. O respondente avalia o grau de importância de uma série de beneficios apresentados segundo uma escala de Likert de cinco pontos. Os resultados apontam para uma maior incidência de beneficios operacionais e relacionados aos funcionários em relação aos benefícios financeiros/administrativos e voltados aos clientes. Os principais beneficios observados são, respectivamente, o aumento da organização interna, a padronização dos processos e o aumento da conscientização para a qualidade.
\end{abstract}

Palavras-chave: qualidade; PBQP-H; benefícios.

\section{Introdução}

A implantação e certificação de sistemas de gestão da qualidade na indústria da construção civil teve início no Brasil em meados dos anos 90. Este movimento foi baseado na série de normas ISO 9000 e posteriormente, o PBQP-H (Programa Brasileiro da Qualidade e Produtividade no Habitat). Paralelamente, surgiram diversas iniciativas com o objetivo de melhorar a qualidade dos produtos e processos, bem como aumentar a competitividade das empresas do setor. Como exemplo, citam-se o QUALIHAB - Programa da Qualidade na Habitação Popular, no Estado de São Paulo (CARDOSO et al., 1998; JESUS, CARDOSO e VIVANCOS, 2002), o QUALIOP Programa de Qualidade das Obras Públicas da Bahia, no Estado da Bahia (PITANGA, 2003) e o 
PQS/ABEF - Programa Setorial da Qualidade da Associação Brasileira de Empresas de Engenharia de Fundações e Geotecnia (ABEF, 2001a, b).

Os benefícios obtidos a partir da implantação de sistemas de gestão da qualidade têm sido pesquisados em todo o mundo. Gustafsson et al. (2001) apontam como benefícios para as empresas certificadas a redução do número de reclamações por parte dos clientes, redução do tempo de entrega e melhoria do processo produtivo. Já em pesquisa realizada na Austrália por Beattie e Sohal (1999), os principais efeitos da certificação são a melhoria dos processos e dos procedimentos. De maneira similar, Ofori e Gang (2001) apontam a melhoria dos procedimentos operacionais, juntamente com a melhoria da imagem da empresa, como os principais benefícios da certificação por parte de empresas construtoras de Singapura.

Um estudo específico a respeito dos benefícios decorrentes da implantação da ISO 9000 é apresentado por Casadesús, Giménez e Heras (2001), a partir de uma pesquisa realizada com 502 empresas de vários setores de atuação na Espanha. Os autores dividem os benefícios em dois grupos, ou seja, benefícios internos (relacionados aos recursos humanos e a aspectos operacionais) e benefícios externos (relacionados aos clientes e aspectos financeiros). Os principais benefícios internos são:

1 Melhoria na definição e padronização dos procedimentos de trabalho;

2 Melhoria na definição das responsabilidades e obrigações dos funcionários;

3 Aumento da confiança da empresa em sua qualidade;

4 Aumento do comprometimento com o trabalho;

5 Redução de improvisações através da melhoria das normas de procedimentos;

6 Aumento da satisfação com o trabalho;

7 Melhoria na comunicação entre a gerência e os funcionários.

Conforme os autores, o efeito mais positivo da padronização na gestão das operações é a redução de erros e defeitos durante o processo produtivo, citado por $91 \%$ das empresas consultadas. Também se observa redução no tempo de produção e entrega dos produtos, bem como redução de custos operacionais. Quanto aos benefícios externos, merecem destaque os seguintes:

1 Melhor resposta aos requerimentos dos clientes;

2 Penetração em novos mercados;

3 Melhoria nas relações com os consumidores;

4 Redução das auditorias por parte dos clientes;

5 Aumento da satisfação dos consumidores;

6 Queda no número de reclamações;

7 Elevação da repetição de compras;

8 Aumento da fatia de mercado. 
Observa-se que grande parte das empresas analisada acredita ter se beneficiado com a certificação. Além disso, 96\% dessas organizações consideram o padrão ISO 9000 um bom sistema de garantia da qualidade, ao passo que muitos gerentes acreditam que o sistema pode ser expandido para incluir questões ambientais e relacionadas à saúde e segurança no trabalho (CASADESÚS, GIMÉNEZ e HERAS, 2001).

Na Bélgica, Vloeberghs e Bellens (1996) apresentam uma pesquisa com 290 empresas de vários setores, certificadas na ISO 9000. Os autores relatam como principais benefícios a melhoria dos processos e procedimentos internos das organizações, tais como a clara definição de responsabilidades, menor número de improvisações e estrutura organizacional mais visível. Entretanto, não se observam melhorias relacionadas à comunicação, comprometimento, treinamento ou redução dos custos da qualidade. Em relação aos benefícios externos, as empresas apresentam melhoria no relacionamento com clientes que exigem a certificação, de modo a prestar um serviço melhor, o que leva as empresas a obterem vantagens comerciais.

A situação da certificação nas normas ISO 9000 na Suécia é apresentada por Poksinska, Dahlgaard e Marc (2002), mediante um estudo com 135 empresas. Quanto aos benefícios da certificação, 50\% das empresas declaram que receberam substanciais benefícios com a ISO 9000 , $35 \%$ declaram moderados benefícios e $8 \%$ benefícios muito substanciais. Os benefícios mais importantes segundo a avaliação das empresas são, respectivamente, a melhoria dos procedimentos internos, melhoria da qualidade, melhoria da imagem da organização, aumento da satisfação dos consumidores, maior precisão no prazo de entrega aos consumidores e melhoria da moral dos funcionários. Também são relacionados outros benefícios menos substanciais, como a melhoria da produtividade, o aumento da fatia de mercado, a redução de custos e a manutenção ou aumento das margens de lucro.

Heras, Dick e Casadesús (2002) analisam a relação existente entre a certificação e a performance financeira das empresas. O estudo compara a performance financeira de 400 empresas certificadas na ISO 9000 com 400 empresas que não são certificadas, todas localizadas na Espanha, a partir de dados obtidos de auditorias financeiras de um período de cinco anos. Os resultados demonstram que as empresas certificadas possuem melhor desempenho financeiro. Entretanto, não é possível afirmar que a certificação é a causa da melhor performance, uma vez que tais empresas também apresentam um melhor desempenho antes da certificação. Os autores concluem que as empresas de melhor desempenho possuem uma maior propensão a adotar a certificação.

Costa (2003) analisa a relação entre qualidade e competitividade com cinco empresas construtoras. $\mathrm{O}$ autor conclui que a certificação colabora para que as empresas obtenham uma melhoria de performance em suas operações internas, o que possibilita para que as empresas coloquem produtos e serviços de melhor qualidade no mercado, com preços e condições. 
Entretanto, a certificação não leva as empresas a interagir com outros atores sociais, através do diálogo e aprendizagem, de forma a influenciar outros fatores externos que afetam direta e indiretamente o desempenho competitivo das organizações. Isto faz com que diversas oportunidades de melhoria no desempenho competitivo sejam perdidas.

Observa-se, portanto, que a percepção de benefícios por parte das empresas refere-se principalmente a melhoria dos processos e procedimentos. Outros benefícios também são comuns, como a melhoria da imagem da empresa, a clara definição de responsabilidades, a redução de prazos e o aumento da satisfação dos clientes e funcionários.

Silveira et al. (2002) descrevem a implementação do PBQP-H em uma empresa que atua nas áreas de construção civil, de incorporação imobiliária e de engenharia em infra-estrutura, com clientes particulares e públicos, no Estado do Rio Grande do Norte. Os principais benefícios percebidos são a melhoria da organização da empresa e do canteiro de obras, a definição clara de atribuições relatadas no manual de descrição de funções e nos procedimentos operacionais, a padronização de processos, a racionalização de processos e a melhoria da mão-de-obra, devido ao treinamento oferecido para a execução dos serviços através dos procedimentos e fichas de verificação de serviços e conseqüente melhoria da qualidade do produto final.

Melgaço et al. (2004) apresentam uma pesquisa realizada com 36 empresas construtoras da região metropolitana de Belo Horizonte. Segundo os autores, as principais vantagens obtidas com a certificação referem-se a padronização de processos, que levou a um efetivo controle, com a redução da variabilidade dos mesmos, a redução dos desperdícios e do retrabalho, além da maior qualificação da mão-de-obra, devido ao treinamento.

A seguir, apresenta-se o método e o resultado obtido por meio de uma pesquisa realizada na região metropolitana de Florianópolis/SC, com empresas construtoras certificadas no PBQP-H, a respeito da percepção de benefícios advindos da implantação de sistemas de gestão da qualidade.

\section{Método de pesquisa}

O levantamento foi realizado entre os meses de julho e outubro de 2005. Neste período, haviam 38 construtoras certificadas no nível A do PBQP-H no Estado de Santa Catarina. Foram contatadas 21 empresas construtoras das cidades de Florianópolis e São José. Entretanto, sete empresas não demonstraram interesse em colaborar com a pesquisa. Deste modo, o presente levantamento conta com a participação de 14 empresas. Optou-se por pesquisar apenas empresas do nível A porque estas já estão com o processo de implantação completamente concluído, de modo a fornecer uma visão mais ampla e fundamentada a respeito do sistema e do programa. 
A pesquisa objetiva determinar a percepção dessas empresas quanto aos principais benefícios obtidos com a implantação e certificação de sistemas de gestão da qualidade. Esta pesquisa é realizada sob a forma de uma entrevista estruturada, baseada em um questionário, com o responsável da qualidade das empresas. O entrevistado expressa sua percepção sobre cada item de acordo com uma escala de um a cinco (Likert).

Todas as questões e os itens que constam no questionário foram baseados em pesquisas similares nacionais e internacionais, notadamente referente à certificação na norma ISO 9000. Uma vez que há compatibilidade entre a ISO 9001:2000 e o PBQP-H, não há problema em se comparar tais pesquisas. Além disso, diversas empresas pesquisadas também possuem a certificação ISO 9001:2000. Em todo momento o entrevistado pôde comentar cada item livremente, o que fornece informações mais substanciais do que a simples informação do nível de percepção, de modo a permitir uma melhor interpretação dos dados obtidos.

O autor visitou pessoalmente cada empresa para solicitar sua colaboração na pesquisa. Optou-se pela realização de entrevistas para obter-se uma maior quantidade de informações, de modo a proporcionar um melhor entendimento sobre o processo de implantação do sistema de gestão da qualidade e da situação atual do sistema nas empresas. Além disso, a presença do autor permite o esclarecimento dos itens do questionário, de modo a fornecer maior confiabilidade às respostas.

Os dados obtidos foram analisados com auxílio de uma planilha eletrônica. Para cada item foram determinados a média e o desvio-padrão. Realizou-se também uma análise de freqüência das respostas quanto à pontuação na escala de um a cinco. Assim, procedeu-se a análise quantitativa através dos dados obtidos, que podem ser complementados e justificados por uma análise de cunho qualitativo, baseada nos comentários realizados pelos entrevistados. A seguir, apresentam-se os resultados obtidos.

\section{Resultados}

Apresentam-se aqui os principais benefícios verificados pelas 14 empresas pesquisadas durante o processo de implantação do sistema de gestão da qualidade. As empresas consultadas não possuem instrumentos de medida para a grande maioria dos benefícios listados a seguir. Deste modo, a avaliação aqui presente é baseada na percepção pessoal do entrevistado. Os benefícios aqui apresentados estão divididos em quatro categorias, de forma a facilitar sua análise e entendimento: beneficios operacionais, benefícios financeiros/administrativos, benefícios relacionados aos clientes e benefícios relacionados aos funcionários. 


\subsection{Benefícios operacionais}

Os benefícios operacionais compreendem aqueles relacionados ao processo produtivo, como a maior organização, redução de desperdício e aumento da produtividade. A Tabela 1 apresenta a média e desvio-padrão dos benefícios operacionais observados pelas empresas, bem como a porcentagem das empresas segundo seu posicionamento na escala de 1 a 5 . Observa-se que as questões relativas à maior organização e padronização gerada pelo sistema representam os principais benefícios percebidos pelas empresas. A seguir, analisa-se separadamente cada um dos itens apresentados.

Tabela 1 Benefícios operacionais

\begin{tabular}{|c|c|c|c|c|c|c|c|}
\hline & & & \multicolumn{5}{|c|}{ Distribuição das notas } \\
\hline & & & 1 & 2 & 3 & 4 & 5 \\
\hline Maior organização interna & 4,71 & 0,47 & $0 \%$ & $0 \%$ & $0 \%$ & $29 \%$ & $71 \%$ \\
\hline Padronização dos processos & 4,64 & 0,63 & $0 \%$ & $0 \%$ & $7 \%$ & $22 \%$ & $71 \%$ \\
\hline Redução de desperdício & 4,00 & 0,68 & $0 \%$ & $0 \%$ & $21 \%$ & $58 \%$ & $21 \%$ \\
\hline Redução de retrabalhos & 3,93 & 0,92 & $0 \%$ & $7 \%$ & $21 \%$ & $43 \%$ & $29 \%$ \\
\hline Melhoria no gerenciamento da obra & 3,93 & 0,83 & $0 \%$ & $7 \%$ & $14 \%$ & $58 \%$ & $21 \%$ \\
\hline Redução das não-conformidades & 3,64 & 0,63 & $0 \%$ & $0 \%$ & $43 \%$ & $50 \%$ & $7 \%$ \\
\hline Definição clara de responsabilidades & 3,64 & 1,08 & $0 \%$ & $14 \%$ & $36 \%$ & $21 \%$ & $29 \%$ \\
\hline Aumento da produtividade & 3,50 & 0,85 & $7 \%$ & $0 \%$ & $29 \%$ & $64 \%$ & $0 \%$ \\
\hline Redução no prazo de entrega das obras & 1,43 & 0,76 & $72 \%$ & $14 \%$ & $14 \%$ & $0 \%$ & $0 \%$ \\
\hline
\end{tabular}

Com média igual a 4,71, a organização interna é o maior benefício observado pelas empresas pesquisadas. A padronização dos processos também aparece com um dos grandes benefícios da certificação. Estes dois itens receberam nota máxima por $71 \%$ das empresas entrevistadas, de acordo com a Tabela 1. De fato, a padronização dos processos colabora muito para a melhoria da organização interna.

$\mathrm{Na}$ Empresa G, a organização interna melhorou muito depois da implantação do programa, principalmente com o uso de computadores. Todas as cotações com fornecedores são realizadas pela internet. A empresa desenvolveu um software próprio para auxiliar o controle de documentos e procedimentos. Boa parte da comunicação entre as pessoas do escritório é feita por e-mail. Além disso, a empresa utiliza um software para gerenciar construtoras, o SIENGE - Sistema Integrado de Engenharia. Este software também é utilizado pelas Empresas E e H.

A padronização dos processos é a grande vantagem do programa, segundo a Empresa B. É apontada como a principal melhoria pela Empresa F, que possui grande preocupação com a padronização e organização da empresa e das obras. A seguir, os próximos benefícios mais relatados são a redução de desperdícios e de retrabalhos. A redução de desperdícios ocorre, em 
geral, devido à maior organização do processo produtivo, maior qualificação e conscientização dos funcionários, o que reduz o desperdício de material. A maior qualificação também leva a uma redução do número de retrabalhos. A redução dos retrabalhos é o foco atual da Empresa $\mathrm{F}$ que, embora já tenha observado uma redução substancial, observa que ainda há muitas oportunidades de melhoria.

Já a melhoria no gerenciamento das obras deve-se em parte à introdução de técnicas de programação da produção, que é um dos requisitos do PBQP-H. A maior padronização dos processos, o maior controle e a realização de registros também colaboram para a melhoria no gerenciamento das obras.

A definição clara de responsabilidades proporcionada pelo programa é vista por algumas empresas como um grande benefício, por eliminar dúvidas e discussões a respeito das responsabilidades de cada indivíduo na organização. Conforme a Empresa $\mathrm{H}$, o programa proporciona maior integração entre os departamentos. Uma vez que todos estão informados do andamento das tarefas, pode-se antecipar os possíveis problemas, de modo a evitar gastos maiores após a ocorrência de algum problema.

Conforme a Empresa M, o programa trouxe uma hierarquia mais clara dentro da empresa, de modo que todos sabem exatamente quais são suas funções e o que necessitam para desempenha-las adequadamente. Entretanto, como se observa na Tabela 1, as opiniões são bastante variáveis, uma vez que apresenta o maior desvio-padrão dentre os itens analisados.

As empresas relatam uma redução razoável das não-conformidades, uma vez que 93\% das empresas atribuíram nota 3 ou 4. Entretanto, essas empresas não possuem dados sobre nãoconformidades referentes ao período anterior à implantação do programa. Muitas vezes, o próprio conceito de não-conformidade era ignorado. De acordo com um dos engenheiros entevistados, antes do programa não havia conhecimento sobre não-conformidades. Então, quando o início do controle, o número aumentou muito, mas agora começa a reduzir. O maior controle proporcionado pelo sistema possibilita o conhecimento das não-conformidades, de modo a fornecer subsídios para as empresas tomarem ações corretivas e preventivas.

O aumento da produtividade é o penúltimo benefício em termos de média, com o valor de 3,50. Entretanto, 64\% das empresas atribuem nota 4 para este item, conforme a Tabela 1, o demonstra que há um certo aumento da produtividade devido à melhorias estruturais e organizacionais proporcionadas pelo programa.

Dentre os benefícios operacionais, a redução no prazo de entrega das obras é o menos citado. Apresenta uma média igual a 1,73 e $72 \%$ das empresas afirmam que o programa não influencia no prazo, conforme a Tabela 1. Em geral, as empresas afirmam que sempre cumprem com os prazos estabelecidos e que isso depende mais de questões financeiras. 


\subsection{Benefícios financeiros/administrativos}

Nenhuma das empresas consultadas possui formas de avaliação da qualidade em termos financeiros ou administrativos. Há três empresas empatadas com a maior média nesta categoria, as Empresas C, F e H, com média 3,40. A Tabela 2 apresenta a média, desvio-padrão e a distribuição das porcentagens atribuídas a cada um dos benefícios financeiros e administrativos pesquisados junto às construtoras.

Tabela 2 Benefícios financeiros/administrativos

\begin{tabular}{|c|c|c|c|c|c|c|c|}
\hline & & & \multicolumn{5}{|c|}{ Distribuição das notas } \\
\hline & & & 1 & 2 & 3 & 4 & 5 \\
\hline Melhoria no gerenciamento da empresa & 3,29 & 1,33 & $14 \%$ & $7 \%$ & $37 \%$ & $21 \%$ & $21 \%$ \\
\hline Maior facilidade de conseguir financiamento & 2,93 & 1,77 & $36 \%$ & $7 \%$ & $21 \%$ & $0 \%$ & $36 \%$ \\
\hline Aumento da competitividade & 2,64 & 1,50 & $36 \%$ & $7 \%$ & $29 \%$ & $14 \%$ & $14 \%$ \\
\hline Redução de custos & 2,21 & 1,37 & $43 \%$ & $7 \%$ & $36 \%$ & $7 \%$ & $7 \%$ \\
\hline Aumento da lucratividade & 1,57 & 0,85 & $65 \%$ & $14 \%$ & $21 \%$ & $0 \%$ & $0 \%$ \\
\hline
\end{tabular}

A melhoria no gerenciamento da empresa apresenta a maior média entre os benefícios financeiros e administrativos, com o valor de 3,29. Observa-se que, mesmo sendo o maior nesta categoria, este valor é bem inferior àqueles observados nas outras categorias, onde aparecem benefícios com média superior a 4 . Outro aspecto relevante diz respeito a grande variabilidade nas opiniões dos entrevistados, como pode-se visualizar na Tabela 2.

Segundo a Empresa B, o programa é voltado para a obra. A empresa não dispõe de indicadores financeiros ou econômicos que demonstrem os benefícios em termos monetários. Também não possui procedimentos para a área administrativa e contábil, em parte por falta de interesse da direção, que prefere investir nas obras a realizar melhorias gerenciais.

Uma vez que a certificação é um requisito para que as construtoras realizem financiamentos junto à Caixa Econômica Federal, as empresas pesquisadas afirmam que possuem maior facilidade para obter financiamento. Entretanto, conforme a Empresa G, que realiza financiamentos freqüentemente, estar em dia com o certificado não é sinônimo de obter financiamento. Segundo o engenheiro, depende muito mais da vontade do órgão financiador em fornecer o financiamento: "Quando eles querem emprestar dinheiro, é fácil. Quando não querem, sempre encontram alguma coisa pra complicar. É muita burocracia". 
Quanto ao aumento de competitividade, apenas duas empresas atribuíram nota 5 a esse item, que possui média geral de 2,64. A Empresa $\mathrm{F}$ afirma que o programa agrega muito à empresa e relata grande aumento de competitividade, até por ser a primeira construtora da cidade a obter a certificação. Algumas empresas, como a Empresa A, por exemplo, observam aumento de competitividade devido ao programa somente em termos de publicidade e marketing. Já $36 \%$ das empresas não observam aumento de competitividade devido ao programa, conforme a Tabela 2.

Algumas empresas afirmam haver uma redução de custos após a implantação do PBQP-H, proporcionada principalmente pela maior organização do processo produtivo, pela redução de desperdício e de retrabalhos. Entretanto, esta redução de custos não se converte integralmente em aumento de lucratividade, uma vez que o sistema gera outros custos, relacionados com as auditorias, consultorias e aumento de efetivo para cumprir os requisitos do programa. Das empresas consultadas, 43\% afirmam não haver redução de custos e $65 \%$ afirmam não haver aumento de lucratividade.

Para a Empresa A, o programa não se presta para a redução de custos, pois não é esse seu foco. De acordo com a empresa, o programa visa a padronização dos processos. Já a Empresa I afirma que inicialmente o sistema gera um aumento de custos, devido a consultorias e auditorias. $\mathrm{O}$ engenheiro salienta que é necessário tempo para que o programa gere uma redução de custos por meio da redução de desperdícios e retrabalhos.

\subsection{Benefícios relacionados aos clientes}

Como se pode observar pela Tabela 3, nem todas as empresas constatam beneficios relacionados aos clientes. As Empresas D e L merecem destaque quanto aos benefícios relacionados aos clientes, de acordo com o apêndice $\mathrm{C}$, pois apresentam a maior média nesta categoria. Isto demonstra grande preocupação com a satisfação do cliente, o que se reflete em redução do número de solicitações para assistência técnica e melhoria da imagem da empresa perante a sociedade.

Tabela 3 Benefícios relacionados aos clientes

\begin{tabular}{l|c|c|c|c|c|c|c}
\hline \multirow{2}{*}{} & \multirow{3}{*}{} & & \multicolumn{5}{|c}{ Distribuição das notas } \\
\cline { 4 - 7 } & & & $\mathbf{1}$ & $\mathbf{2}$ & $\mathbf{3}$ & $\mathbf{4}$ & $\mathbf{5}$ \\
\hline Redução do número de reclamações / assistência técnica & 4,07 & 1,14 & $7 \%$ & $0 \%$ & $14 \%$ & $36 \%$ & $43 \%$ \\
\hline Aumento da satisfação com o produto & 3,64 & 1,55 & $21 \%$ & $0 \%$ & $7 \%$ & $36 \%$ & $36 \%$ \\
\hline Melhoria da imagem da empresa & 3,57 & 1,50 & $21 \%$ & $0 \%$ & $7 \%$ & $43 \%$ & $29 \%$ \\
\hline Redução do preço dos imóveis para o usuário final & 1,29 & 0,73 & $86 \%$ & $0 \%$ & $14 \%$ & $0 \%$ & $0 \%$ \\
\hline
\end{tabular}


Segundo a avaliação das empresas consultadas, a redução do número de reclamações é o maior benefício relacionado aos clientes, com média igual a 4,07. A redução do número de solicitações para assistência técnica indica que o produto apresenta menos defeitos identificados após a entrega. Na Empresa G, por exemplo, o número de reclamações pós-entrega diminuiu após a certificação, de acordo com seus indicadores. A empresa possui grande preocupação com a qualidade uma vez que, segundo o engenheiro, os clientes estão cada vez mais exigentes e não admitem defeitos na construção.

A Empresa F apresenta grande preocupação com o atendimento ao cliente, tanto que possui um departamento específico para assuntos relacionados aos clientes. O engenheiro afirma que, às vezes, a empresa presta serviços mesmo após o prazo legal de cinco anos. Caso contrário, a empresa fornece orientações ao cliente sobre a melhor forma de resolver o problema, materiais e mão-deobra adequados.

Diversas empresas consultadas realizaram apenas uma pesquisa de satisfação dos clientes até o momento da pesquisa. Isso ocorre devido ao longo tempo de ciclo de cada empreendimento, que geralmente leva um ano para ser concluído. Uma vez que tais empresas atingiram a certificação plena a menos de um ano, ainda não se realizaram outras pesquisas, de modo a verificar o aumento da satisfação dos clientes.

A Empresa $\mathrm{F}$ realiza pesquisas de satisfação do cliente de forma bastante completa e abrangente, com padrões exigentes de desempenho. Os resultados demonstram que a empresa atinge as metas estipuladas satisfatoriamente. A maioria dos clientes afirma que recomendariam a compra ou voltariam a comprar outro apartamento desta empresa.

A melhoria da imagem da empresa perante a sociedade é citada por várias empresas. Os entrevistados afirmam que o sistema de gestão da qualidade trás mudanças nos canteiros de obra, principalmente relativas à maior organização e limpeza. Essas melhorias são percebidas pelos clientes que visitam as obras, o que leva ao aumento de credibilidade da empresa. Além disso, algumas empresas utilizam o selo do PBQP-H como instrumento de marketing em suas campanhas publicitárias.

Algumas empresas não utilizam o PBQP-H como instrumento de marketing, como a Empresa E, por exemplo. A empresa possui um departamento de marketing que realiza as campanhas publicitárias com base nas características do produto. Isto se justifica porque os imóveis possuem alto padrão de acabamento, destinados a compradores com alto poder aquisitivo. Tais clientes são muito exigentes quanto à qualidade do imóvel, de modo que a participação no programa não representa um diferencial para a compra. 
Uma das empresas consultadas não observa melhoria da sua imagem perante a sociedade. Segundo a empresa, as características do produto são muito mais importantes para a decisão de compra do cliente do que o fato de a empresa ser certificada ou não. Muitos clientes não sabem o que é PQBP-H, de modo que, se a empresa não o informar, o cliente nem toma conhecimento de que a empresa é certificada.

A redução do preço dos imóveis para o usuário final apresenta a menor média de todos os benefícios citados nas quatro categorias, com o valor de 1,29, conforme a Tabela 3. Apenas duas empresas afirmam que houve uma redução relativa do preço dos imóveis para o usuário final devido a melhorias provocadas pela gestão da qualidade. Todas as demais empresas afirmam que o preço de venda é função do mercado. Assim, uma eventual redução de custos se converteria em lucratividade para tais empresas. Cabe salientar que algumas empresas produzem imóveis de alto padrão, localizados em áreas nobres de Florianópolis. Estes imóveis são direcionados para pessoas com alto poder aquisitivo e investidores de outros estados e até mesmo de outros países. De modo geral, as empresas não demonstram intenções em reduzir o preço dos imóveis enquanto houver mercado comprador. Como diz um dos entrevistados, "esses apartamentos são relativamente caros, mas um artista ou empresário de São Paulo vem aqui e acha barato, então compra”.

Para a Empresa A, o preço de venda aumentou em decorrência da melhor qualidade do produto e dos processos, devido à necessidade de maior número de funcionários para realizar as inspeções e ensaios, além do uso de materiais de melhor qualidade. Na Empresa F, o preço também é um pouco superior à média, devido a maior qualidade, solidez e garantia que o cliente tem de que receberá o que deseja.

\subsection{Benefícios relacionados aos funcionários}

Os benefícios relacionados aos funcionários estão listados na Tabela 4, que apresenta a média, desvio-padrão e a distribuição das porcentagens atribuídas a cada item. Uma das empresas consultadas apresenta maior enfoque nos funcionários. A empresa disponibiliza uma sala de aula no canteiro de obras para a alfabetização e conclusão dos estudos dos funcionários desde 2003, no início do processo de implantação do sistema de gestão da qualidade. A empresa também disponibiliza um médico e um ambulatório para atendimento dos funcionários e familiares. Conforme o engenheiro entrevistado, o programa teve maior efeito na obra e os funcionários são os maiores beneficiados. Há mais integração, os funcionários sabem o que devem fazer e porquê. Assim, a empresa procura evitar o autoritarismo, através de uma postura mais participativa e da valorização dos funcionários. 
Tabela 4 Benefícios relacionados aos funcionários

\begin{tabular}{l|c|c|c|c|c|c|c}
\hline & \multirow{2}{*}{} & \multirow{3}{*}{} & & \multicolumn{4}{|c}{ Distribuição das notas } \\
\cline { 5 - 7 } & & & $\mathbf{1}$ & $\mathbf{2}$ & $\mathbf{3}$ & $\mathbf{4}$ & $\mathbf{5}$ \\
\hline Aumento da conscientização para a qualidade & 4,57 & 0,51 & $0 \%$ & $0 \%$ & $0 \%$ & $43 \%$ & $57 \%$ \\
\hline Aumento da qualificação dos trabalhadores & 4,21 & 0,70 & $0 \%$ & $0 \%$ & $14 \%$ & $50 \%$ & $36 \%$ \\
\hline Melhoria da comunicação interna & 4,21 & 0,70 & $0 \%$ & $0 \%$ & $14 \%$ & $50 \%$ & $36 \%$ \\
\hline Melhoria da saúde e segurança no trabalho & 4,00 & 1,11 & $7 \%$ & $0 \%$ & $14 \%$ & $43 \%$ & $36 \%$ \\
\hline Aumento do trabalho em equipe & 3,93 & 0,62 & $0 \%$ & $0 \%$ & $21 \%$ & $65 \%$ & $14 \%$ \\
\hline Aumento da satisfação com o trabalho & 3,93 & 0,92 & $0 \%$ & $7 \%$ & $21 \%$ & $43 \%$ & $29 \%$ \\
\hline Aumento das sugestões dos funcionários & 3,36 & 1,39 & $14 \%$ & $7 \%$ & $36 \%$ & $14 \%$ & $29 \%$ \\
\hline Redução da rotatividade & 1,93 & 1,14 & $43 \%$ & $36 \%$ & $14 \%$ & $0 \%$ & $7 \%$ \\
\hline Redução do absenteísmo & 1,71 & 1,14 & $57 \%$ & $29 \%$ & $7 \%$ & $0 \%$ & $7 \%$ \\
\hline
\end{tabular}

Com relação aos funcionários, o aumento da conscientização para a qualidade é o maior benefício observado, com média igual a 4,57 e desvio-padrão de apenas 0,51 , o que demonstra grande consenso entre as empresas pesquisadas, que atribuíram apenas nota 4 ou 5 , conforme a Tabela 4.

Para a Empresa C, a maior conscientização é decorrente do aumento do envolvimento dos funcionários em relação à qualidade. Este envolvimento deve-se a postura que as pessoas em cargo de liderança têm frente aos funcionários, principalmente o técnico em edificações, que já possuía conhecimentos sobre gestão da qualidade antes da implementação do sistema. Tal postura se traduz sob a forma de respeito, valorização, participação, possibilidade de aprimoramento e conhecimento das conseqüências do trabalho sem qualidade. Segundo a Empresa G, o aumento da conscientização para a qualidade acarreta em redução de desperdícios, de não-conformidades e de retrabalhos.

$\mathrm{O}$ aumento da qualificação dos trabalhadores deve-se em parte à exigência da realização de treinamento para todos os novos funcionários da empresa. $\mathrm{Na}$ Empresa $\mathrm{C}$, os funcionários são incentivados a buscar maior qualificação, seja através da realização de cursos, treinamentos ou do simples esclarecimento de dúvidas na obra com o engenheiro, técnico ou mestre-de-obras. $\mathrm{O}$ fato de que funcionários mais produtivos podem ganhar mais é um grande motivador para a busca por aperfeiçoamento.

A Empresa E investe muito em treinamento, uma vez que os imóveis são de alto padrão e os clientes são muito exigentes, a empresa procura entregar os imóveis sem qualquer falha construtiva. A Empresa I também fornece treinamentos periódicos e inclusive convida fabricantes de materiais para conferir palestras e demonstrações para os funcionários, de modo a mantê-los atualizados.

A melhoria da comunicação interna apresenta a mesma média e desvio-padrão do item anterior, ou seja, 4,21 e 0,70, respectivamente, de acordo com a Tabela 4. As empresas afirmam que o uso de registros documentados auxilia na comunicação entre obra e escritório, pois muitas 
informações deixaram de ser transmitidas oralmente. Deste modo, reduziu o número de equívocos e esquecimentos por não se ter as informações corretas no momento necessário. A maior participação dos funcionários também colabora para a melhoria da comunicação.

A melhoria da saúde e segurança no trabalho aparece na quarta posição dos maiores benefícios relacionados aos funcionários, com média igual a 4,00. As condições de saúde e segurança no trabalho melhoram com a implantação de sistemas de gestão da qualidade, que inicia geralmente com o programa $5 \mathrm{~S}$ 's. Também se tem maior atenção para o cumprimento da norma NR-18 - Condições e Meio Ambiente de Trabalho na Indústria da Construção.

$\mathrm{O}$ aumento do trabalho em equipe é percebido, geralmente, pela maior consciência do conceito de cliente interno, no qual a próxima etapa é cliente da etapa predecessora. Outra forma de estimular o trabalho em equipe é através da maior integração entre os indivíduos. A Empresa $\mathrm{F}$ realiza atividades sociais com o objetivo de promover a integração entre seus funcionários. Um exemplo dessas ações é a reforma de creches. A empresa fornece o material e os funcionários trabalham de graça. Tais ações não são divulgadas, pois a finalidade não é realizar publicidade, mas sim auxiliar essas instituições e promover maior integração na empresa.

O aumento da satisfação com o trabalho é percebido por diversas empresas, proveniente principalmente do aumento da qualidade de vida no trabalho. Na Empresa $\mathrm{C}$, o aumento de satisfação é decorrente do aumento da autonomia e maior valorização dentro da empresa, além dos ganhos advindos da padronização, com a associação de produtividade e qualidade. Ou seja, os funcionários produzem mais e de maneira correta. Já a Empresa F oferece uma série de benefícios aos funcionários, como convênios com farmácias, médicos e dentistas.

O aumento de sugestões dos funcionários, embora tenha média 3,36, apresenta opiniões bastante divergentes, como se observa na Tabela 4. Muitos funcionários não se sentem à vontade para expressar sua opinião. Também falta abertura por parte de certo engenheiros e mestres-deobras para que os funcionários participem mais. Já na Empresa E, por exemplo, observa-se um aumento da participação dos funcionários por meio de caixa de sugestões e reuniões mensais, além da liberdade para que qualquer funcionário possa conversar com o engenheiro e expor seus problemas ou eventuais dúvidas, de modo a criar um clima organizacional favorável à melhoria da qualidade.

A grande maioria (79\%) das empresas afirma que houve pouca ou nenhuma redução da rotatividade devido ao programa, conforme a Tabela 4. Em geral, a rotatividade depende do número de obras em execução e do estágio de cada obra. Muitas vezes as empresas não dispõem de outra obra para remanejar os funcionários, que acabam por ser demitidos. A Empresa I possui funcionários próprios para a maioria dos serviços. Desde que iniciou a implantação do PBQP-H, a rotatividade na empresa reduziu bastante. A principal razão para isso é a melhoria da qualidade de 
vida no trabalho oferecida aos funcionários, tais como benefícios, convênios, treinamento, educação, valorização e maior participação dos trabalhadores.

Com a menor média na categoria $(1,71)$, a redução do absenteísmo foi considerada pequena ou nula por $86 \%$ das empresas. Na Empresa F, por exemplo, observa-se certa redução do absenteísmo a partir da implantação do sistema de gestão da qualidade. A empresa aboliu o uso do cartão-ponto e procura conscientizar os funcionários sobre a importância do seu comprometimento. Já na Empresa I, o absenteísmo reduziu devido à maior valorização e melhoria da qualidade de vida no trabalho.

\section{Conclusões}

Existe uma enorme gama de benefícios que podem ser obtidos a partir da implantação de sistemas de gestão da qualidade. Em geral, as pesquisas apontam para melhoria dos processos e organização da empresa. Neste trabalho, a percepção de benefícios foi dividida em quatro categorias: operacionais, financeiros/administrativos, clientes e funcionários.

A presente pesquisa foi realizada com 14 construtoras da Grande Florianópolis, com o objetivo de identificar a percepção das mesmas em relação aos benefícios advindos da implantação e certificação de sistemas de gestão da qualidade.

Neste grupo de empresas, os principais benefícios operacionais obtidos são a maior organização interna e padronização dos processos. Esses são os dois maiores benefícios dentre todos aqueles listados neste trabalho. A redução de desperdícios e retrabalhos também merece destaque, como conseqüência da maior organização dos processos produtivos e do aumento da conscientização para a qualidade.

Já em relação aos benefícios financeiros/administrativos, tem-se a melhoria no gerenciamento da empresa e a maior facilidade de conseguir financiamento. Cabe observar que as empresas ainda não percebem influência do sistema na lucratividade. É possível que, com mais alguns anos, os benefícios operacionais tornem-se mais substanciais, ao passo em que se reduzam custos ligados à certificação, de modo que o sistema de gestão da qualidade possa refletir benefícios financeiros mais perceptíveis. Além disso, as empresas não possuem formas de avaliar monetariamente seus sistemas de gestão da qualidade. Sabe-se que a certificação é onerosa (consultoria, auditoria, contratação de pessoal para atender aos requisitos e maior tempo dedicado pelas pessoas ao sistema), mas ainda há uma carência no que se refete à medição do retorno obtido através do sistema de gestão da qualidade.

A redução do número de reclamações e solicitações para assistência técnica é o principal benefício em relação aos clientes. Isso é um indicativo de que a qualidade dos produtos entregues 
está cada vez melhor, o que leva a um aumento da satisfação dos clientes. Este é outro importante benefício observado pelas empresas, que demonstram um crescente foco no cliente. A melhoria da imagem da empresa perante a sociedade também é salientada por diversas construtoras, que se utilizam do selo do PBQP-H como instrumento de marketing.

Já os benefícios relacionados aos funcionários são observados principalmente pelo aumento da conscientização para a qualidade, aumento da qualificação dos trabalhadores e melhoria da comunicação interna. Em algumas empresas observa-se uma mudança de postura frente ao funcionário operacional, que ganhou maior importância e consideração dentro da empresa. Isso se reflete na melhoria da qualidade de vida no trabalho para esses operários.

Apesar de todos os benefícios relatados, observa-se que a certificação é apenas uma parte da busca pela melhoria da qualidade. Em geral, muitas empresas preocupam-se mais com a parte burocrática do sistema do que com a busca da melhoria contínua. Assim, o sistema de gestão da qualidade pode ser visto como uma tarefa a mais que sobrecarrega as pessoas e não como um instrumento de melhoria. Torna-se, portanto, necessária a criação de uma cultura voltada para a qualidade dentro das empresas. Para isso, deve-se ter em mente a importância da qualidade, não somente para o atendimento dos requisitos dos clientes ou para a manutenção de um certificado, mas também para a manutenção e melhoria da posição da empresa no mercado.

Deste modo, o presente trabalho procura colaborar para uma melhor compreensão da evolução da qualidade na construção civil, por meio da determinação dos principais benefícios obtidos a partir da implantação e certificação de sistemas de gestão da qualidade. O conhecimento de aspectos relacionados à implantação de sistemas de gestão da qualidade pode auxiliar outras empresas que ainda não completaram ou não iniciaram o processo de certificação.

\begin{abstract}
On the last years, many construction companies has looking for a quality management system certificate, mainly ISO 9001 and PBQP-H. Many authors expound the implantation and certification process but, generally, the papers explain the process of implementation and future expectations. The present work has the objective of identify the companies' perceptions about the benefits to implement and certificate quality management systems. Was made a research with 14 construction companies in Florianópolis city. This research is conducted with structured interviews, based on a questionnaire. The respondents evaluate the importance level of a set of benefits presented with a Likert scale of five points. The results pointed to a higher incidence of operational and worker related benefits in relation to financial/management and clients related benefits. The mainly benefits observed are, respectively, the increase of internal organization, the process standardization and increase of quality conscience.
\end{abstract}

Key-words: quality; PBQP-H; difficulties. 


\section{Referências}

ABEF - Associação Brasileira de Empresas de Engenharia de Fundações e Geotecnia. PSQ - Programa Setorial da Qualidade ABEF - Parte I: Aspectos setoriais, 5 Ed. 2001a. 25 p. Disponível em <http://www.abef.org.br/>. Acesso em: 22 jun. 2005.

ABEF - Associação Brasileira de Empresas de Engenharia de Fundações e Geotecnia. PSQ - Programa Setorial da Qualidade ABEF - Parte II - Sistema de qualificação de empresas de execução de fundações e serviços de geotecnia, 5 Ed. 2001b. 16 p. Disponível em <http://www.abef.org.br/>. Acesso em: 22 jun. 2005.

BEATTIE, Ken R.; SOHAL, Amrik S. Implementing ISO 9000: a study of its benefits among Australian organizations. Total Quality Management, v. 10, n. 1, p. 95-106, 1999.

cross'ref

CARDOSO, Francisco Ferreira; VIVANCOS, Adriano Gameiro; SILVA, Fred Borges; ALBUQUERQUE NETO, Edson Toledo de. Uma primeira avaliação do programa QUALIHAB e de seu impacto nas empresas de construção de edifícios. In: CONGRESSO LATINO-AMERICANO TECNOLOGIA E GESTÃO NA PRODUÇÃO DE EDIFÍCIOS, 1998, São Paulo. Anais... São Paulo: PCC-USP, 1998, p. 609 - 618.

CASADESÚS, Martí; GIMÉNEZ, Gerusa; HERAS, Iñaki. Benefits of ISO 9000 implementation in Spanish industry. European Business Review, v. 13, n. 6, p. 327-335, 2001.

cross'

COSTA, Carlos Alberto da. Competitividade sistêmica na construção civil: a contribuição efetiva dos sistemas de gestão da qualidade (NBR ISO 9001:2000). 2003. 175 p. Dissertação (Mestrado em Engenharia de Produção) Universidade Federal de Santa Catarina. Florianópolis, 2003.

GUSTAFSSON, Roberth; KLEFSJÖ, Bengt; BERGGREN, Eric; GRANFORS-WELLEMETS, Ulrika. Experiences from implementing ISO 9000 in small enterprises: a study of Swedish organisations. The TQM Magazine, v. 13, n. 4, p. 232-246, 2001.

cross ${ }^{\text {ref }}$

HERAS, Iñaki; DICK, Gavin P. M.; CASADESÚS, Martí. ISO 9000 registration's impact on sales and profitability. A longitudinal analysis of performance before and after accreditation. International Journal of Quality and Reliability Management, v. 19, n. 6, p. 774-791, 2002.

cross'

JESUS, Cláudia N.; CARDOSO, Francisco F.; VIVANCOS, Adriano G. Cadeia produtiva e programas setoriais da qualidade dos setores de obras e de gerenciamento. Importância da retroalimentação das ações para o caso do programa QUALIHAB. In: ENCONTRO NACIONAL DE TECNOLOGIA DO AMBIENTE CONSTRUÍDO, IX, 2002, Foz do Iguaçu. Anais... Foz do Iguaçu-PR, 2002, p. 761-766.

MELGAÇO, Luís A.; VIEIRA, Maria da Penha C.; ANDERY, Paulo; ROMEIRO FILHO, Eduardo. Visão prospectiva sobre a gestão operacional em construtoras certificadas no PBQP-H. In: ENCONTRO NACIONAL DE TECNOLOGIA DO AMBIENTE CONSTRUíDO, X, 2004, São Paulo. Anais... São Paulo-SP, 2004, 11 p.

OFORI, George; GANG, Gu. ISO 9000 certification of Singapore construction enterprises: its costs and benefits and its role in the development of the industry. Engineering, Construction and Architectural Management, v. 8, n. 2, p. $145-157,2001$.

cross ${ }^{\text {ref }}$

PITANGA, Carlos Roberto Oliveira. O sistema de gestão da qualidade proposto pelo programa de qualidade em obras públicas (QUALIOP) do governo do estado da Bahia e a sua aplicação no setor de edificações. 2003.152 p. Dissertação (Mestrado em Administração) - Universidade Federal da Bahia, Salvador, 2003.

POKSINSKA, Bozena; DAHLGAARD, Jens Jörn; MARC, Antoni. The state of ISO 9000 certification: a study of Swedish organizations. The TQM Magazine, v. 14, n. 5, p. 297-306, 2002.

cross ref

SILVEIRA, Débora Rocha Dias da; AZEVEDO, Eline Silva de; SOUZA, Dayse da Mata Oliveira de; GOUVINHAS, 
Reidson Pereira. Qualidade na construção civil: um estudo de caso em uma empresa da construção civil no Rio Grande do Norte. In: ENCONTRO NACIONAL DE ENGENHARIA DE PRODUÇÃO, XXII, 2002, Curitiba. Anais... Curitiba-PR, 2002. 8 p.

VLOEBERGHS, Daniel; BELLENS, Jan. Implementing the ISO 9000 standards in Belgium. Quality Progress, v.29, n. 6 , p. 43-48, 1996.

\section{Dados completos dos autores:}

Nome completo: Marcelo Dalcul Depexe, M.Sc.

Filiação institucional: Universidade Federal de Santa Catarina - UFSC

Departamento: Programa de Pós-Graduação em Engenharia de Produção - PPGEP

Endereço completo para correspondência: Rua Eng. Antônio Batista Ribas, 151, casa 3 - Tarumã.

Curitiba/PR - Brasil. CEP 82.800-130

Telefones para contato: (41) 3330-7218

e-mail: marcelodepexe@yahoo.com.br

Nome completo: Edson Pacheco Paladini, Dr.

Filiação institucional: Universidade Federal de Santa Catarina - UFSC

Departamento: Programa de Pós-Graduação em Engenharia de Produção - PPGEP

Função ou cargo ocupado: Professor Titular

Endereço completo para correspondência: CTC/UFSC Cx. postal 476. Florianópolis/SC - Brasil. CEP 88010-970

e-mail:paladini@deps.ufsc.br 